\title{
What factors affect the severity of permanent tooth impaction?
}

\author{
Mariam Al-Abdallah ${ }^{1 *}$ (D) Abeer AlHadidi ${ }^{2}$, Mohammad Hammad ${ }^{3}$ and Najla Dar-Odeh ${ }^{4}$
}

\begin{abstract}
Background: The aim of this study was to investigate the association between the severity of permanent tooth impaction and a number of predefined factors, including tooth type, age, gender, tooth agenesis, microdontia of maxillary lateral incisor, and retained deciduous predecessors.

Methods: A sample of 2979 dental patients, aged 15 to 40 years, was surveyed by two calibrated examiners for permanent tooth impaction (excluding third molars). On panoramic radiographs, the impacted teeth were initially ranked based on their vertical, horizontal, and angular positions, and the ranking was then analysed for distribution by the predefined factors. To test the age factor, patients were divided into younger (15 to $25 \mathrm{yr}$ ) and older (between 25 and $40 \mathrm{yr}$ ) age groups. The statistical significance of the ranked vertical, horizontal, and angular positions of impacted teeth by the investigated factors was determined using the Wilcoxon-Mann-Whitney $\mathrm{U}$ test.
\end{abstract}

Results: The angular position of the impacted teeth was more severe in the older age group $(P=0.012)$ and in females $(P=0.018)$. The maxillary canine had more severe horizontal $(P=0.001)$ and angular $(P=0.003)$ impactions in females. Tooth agenesis was associated with less severe horizontal impaction $(P=0.041)$ in the mandibular second premolar. In addition, microdontia of the maxillary lateral incisor was associated with more severe horizontal impaction in general, and more severe horizontal $(P=0.024)$ and angular $(P=0.010)$ impaction of the mandibular second premolar in particular. Finally, our results showed that a retained deciduous predecessor was linked to a less severe vertical impaction of the mandibular second premolar $(P=0.030)$ and horizontal impaction of the maxillary second premolar $(P=0.037)$ but more severe angular impaction of the mandibular canine.

Conclusions: This study suggests that the more delayed the treatment, being a female, the presence of maxillary lateral incisor with microdontia, and retained lower deciduous canines might be associated with more severe position of the impacted teeth. Because the severity of tooth impaction would follow different patterns when considering the investigated factors, it is mandatory to include such factors during dental diagnoses and the planning of preventive or interceptive interventions for young patients.

Keywords: Impaction, Dental anomalies, Malocclusion, Severity

\section{Background}

The normal development of the occlusion and craniofacial complex is largely dependent on the normal physiological eruption of teeth [1]. Eruption is the process by which a tooth moves axially from its follicle position in the bone into its final functional position in the oral cavity. Following clinical and radiographic assessment, if a tooth is not expected to erupt, as a result of a positional deviation of

\footnotetext{
* Correspondence: m.alabdallah@ju.edu.jo; drmariam76@hotmail.com ${ }^{1}$ Department of Orthodontics, Faculty of Dentistry, The University of Jordan, Amman 11942, Jordan

Full list of author information is available at the end of the article
}

its developing follicle or the presence of a physical barrier in its path, then the tooth is rendered impacted [1-4].

The impaction of permanent teeth (excluding third molars) is a frequent phenomenon, with a reported prevalence ranging from $2.9 \%$ [5] to $13.7 \%$ [5-13]. The most frequently impacted teeth are the canines and second premolars in both jaws with different incidence rates [6-16].

The orthodontic alignment of an impacted tooth to its normal functioning position in the oral cavity may require prolonged and complicated treatment. Prognosis and treatment difficulty can be affected by many factors, some of which are related to the patient, others to features associated

(c) The Author(s). 2018 Open Access This article is distributed under the terms of the Creative Commons Attribution 4.0 International License (http://creativecommons.org/licenses/by/4.0/), which permits unrestricted use, distribution, and reproduction in any medium, provided you give appropriate credit to the original author(s) and the source, provide a link to the Creative Commons license, and indicate if changes were made. The Creative Commons Public Domain Dedication waiver (http://creativecommons.org/publicdomain/zero/1.0/) applies to the data made available in this article, unless otherwise stated. 
with malocclusion, and most importantly, the factors related to the position of the impacted tooth [14-18].

As dentists, we are interested in the prevalence and pattern of impacted teeth, as well as identifying the factors that might affect the severity of the impaction and, consequently, the difficultly and duration of treatment needed $[14,19,20]$. Most previous studies have focused on the prevalence of impacted teeth and described their position in the jaws. Therefore, the aim of the present study is to investigate factors affecting the severity of the impaction of permanent teeth.

\section{Methods}

Digital panoramic radiographs and clinical records for 4258 dental patients aged 15 to 40 years old who attended a university dental hospital between 2011 and 2015 were retrieved for this study. All digital panoramic radiographs were taken with the KODAK 8000 Digital Panoramic System ${ }^{\circ}$ and viewed using the KODAK Dental Imaging Software ${ }^{\circ}$. Patients with incomplete clinical records, craniofacial syndromes and clefts, or previous history of extraction or orthodontic treatments were excluded. Following these criteria, 2979 cases were included in this study (average age $=24.9$ years, males $=$ $45.3 \%$, females $=54.7 \%$ ).

Two calibrated researchers (M.A. and A.A.) examined the selected records concurrently to determine the presence, tooth involved and the position of impaction of permanent teeth (excluding third molars). A tooth was diagnosed as impacted when it was predicted to remain unerupted due to a physical barrier or deflection along its eruption path, or if it remained in the jaw 2 years past the expected eruption time $[2,6,21,22]$. The minimum age for inclusion was 15 years to account for the delayed development and eruption of second premolars, thereby minimizing false-positive findings [23].

The following variables were recorded to describe the vertical, horizontal, and angular positions of each impacted tooth:

1. Vertical position: The distance of the crown of the impacted tooth from the occlusal plane was ranked relative to the adjacent mesial tooth. Horizontal lines were drawn and vertical sectors were formed to locate the impacted tooth vertically $[14,24]$. The ranking of the used sectors were as follows:

- Rank 1: Occlusal to the cemento-enamel junction.

- Rank 2: Within the occlusal half of the root.

- Rank 3: Within the apical half of the root.

- Rank 4: In a position more apical than the apex.

2. Horizontal position: Judged relative to the vertical lines dividing the area adjacent to the impacted tooth [16]. The position of the impacted tooth was then determined relative to the formed sectors. The sectors used were ranked as follows:

- Rank 0: Absence of horizontal overlap.

- Rank 1: Overlap with the distal half of the root of the tooth mesial to the impacted tooth.

- Rank 2: Overlap reaching the mesial half of the root of the tooth mesial to the impacted tooth.

- Rank 3: Overlap reaching the distal half of the root of the second tooth mesial to the impacted tooth.

- Rank4: Overlap reaching the mesial half of the second tooth mesial to the impacted tooth.

- Rank 5: Overlap beyond two adjacent teeth mesial to the impacted tooth.

3. Angular position: Assessed by measuring the angle between the midline and the long axis of the impacted tooth [14-16]. The angle was then ranked as follows:

- Rank 1: less than 30 degrees

- Rank 2: 30-45 degrees

- Rank 3: more than 45 degrees

Data ranking the position of the impacted teeth were pooled and analysed for distribution by age and gender, as well as association with dental anomalies. For the purpose of investigating the significant effects of age on the severity of impacted tooth position, the sample was divided into two groups: adolescents and young adults with an age ranging from 15 to 25 years (the younger age group), and adults between the ages of 25 and 40 (the older age group).

The dental anomalies included in this investigation were:

1) Tooth agenesis: no sign of crown calcification on the radiograph and no evidence or history of loss attributable to caries, periodontal disease, or trauma $[25,26]$.

2) Microdontia of maxillary lateral incisor: mesiodistal width of the crown less than that of the opposing mandibular lateral incisor [27].

3) Retained deciduous tooth: deciduous tooth maintained in the arch with the presence of an impacted permanent successor.

The Statistical Package for Social Sciences (SPSS software for Windows, version 22, Chicago, Illinois) was used for the statistical analysis. The prevalence of impacted teeth in both age groups and genders were compared using a chi-square test. On the other hand, an independent sample t-test was used to compare the number of impacted teeth between the age and gender groups. The Wilcoxon-Mann-Whitney U test was conducted to determine the statistical significance of the 
ranked vertical, horizontal, and angular positions of the impacted teeth by tooth type, age, gender, tooth agenesis, microdontia of upper lateral incisor, and retained deciduous teeth. The level of significance for all tests was set at $P<0.05$.

\section{Results}

From the total of 2979 selected and analysed records, at least one impacted tooth was diagnosed in 189 dental patients $($ males $=46.6 \%$, females $=53.4 \%$, mean age $=$ 23.4 yr., $\mathrm{SD}=7.1$ ). The prevalence of impaction in the younger age group $(n=123)$ was $6.8 \%$, and in the older age group $(n=66)$, the prevalence was $5.6 \%$; there were no significant differences in the prevalence between the two age groups $\left(\mathrm{X}^{2}=1.703, P=0.19\right)$. The total number of impacted teeth was 297, with an average of $1.6 \mathrm{im}$ pacted teeth per patient. The distribution of the $297 \mathrm{im}$ pacted teeth between the maxilla and the mandible is shown in Fig. 1. The four most frequently impacted teeth were the maxillary canine (46.1\%), the mandibular second premolar (28.2\%), the maxillary second premolar $(13.5 \%)$, and the mandibular canine $(8.1 \%)$.

Following the ranking of the position of the impacted teeth in the vertical, horizontal and angular categories, statistical significance testing was carried out to determine if any of the investigated factors affected the severity of impaction (Table 1). When the older age group was compared to the younger age group, there was worsening in the position of the impaction in all three categories with age, but it did not reach a significant level, except for the angle of impaction $(P=0.012)$.
Males and females had comparable rankings for the vertical and horizontal impactions. Nevertheless, the angle of impaction was more severe in females compared to males $(P=0.018)$. On the other hand, ranking of the position of the impacted teeth was lower for patients with tooth agenesis when compared to those with full permanent dentition, but the values were not statistically significant. Microdontia of the maxillary lateral incisor was associated with a higher ranking of the position of the impaction, but again, the values were not significant, except for the horizontal impaction $(P=0.030)$. Although the horizontal impaction of teeth with a retained predecessor was more severe, none of the values were statistically significant.

When the ranking of the position of the impaction of the four most prevalent impacted teeth were compared, it was found that the maxillary canine was the most severely impacted in the vertical, horizontal and angular positions $(P<0.001)$, while the mandibular second premolar was the least severely impacted $(P<0.001)$. The severity of impaction for these four teeth was assessed by age, gender and associated dental anomalies, as shown in Table 2.

Both age groups had comparable severity of impaction of all teeth except for the maxillary canine. The older age group had a significantly more severe angle of impaction $(P=0.012)$ of the maxillary canine compared to the younger age group. Correspondingly, males and females had a similar severity of impaction in all teeth except for the maxillary canine, which had more severe impactions in females in the horizontal $(P=0.001)$ and angular $(P=0.003)$ positions.

Tooth agenesis did not affect the severity of impaction, except for in the mandibular second premolar where the

\section{Maxillary teeth}

137

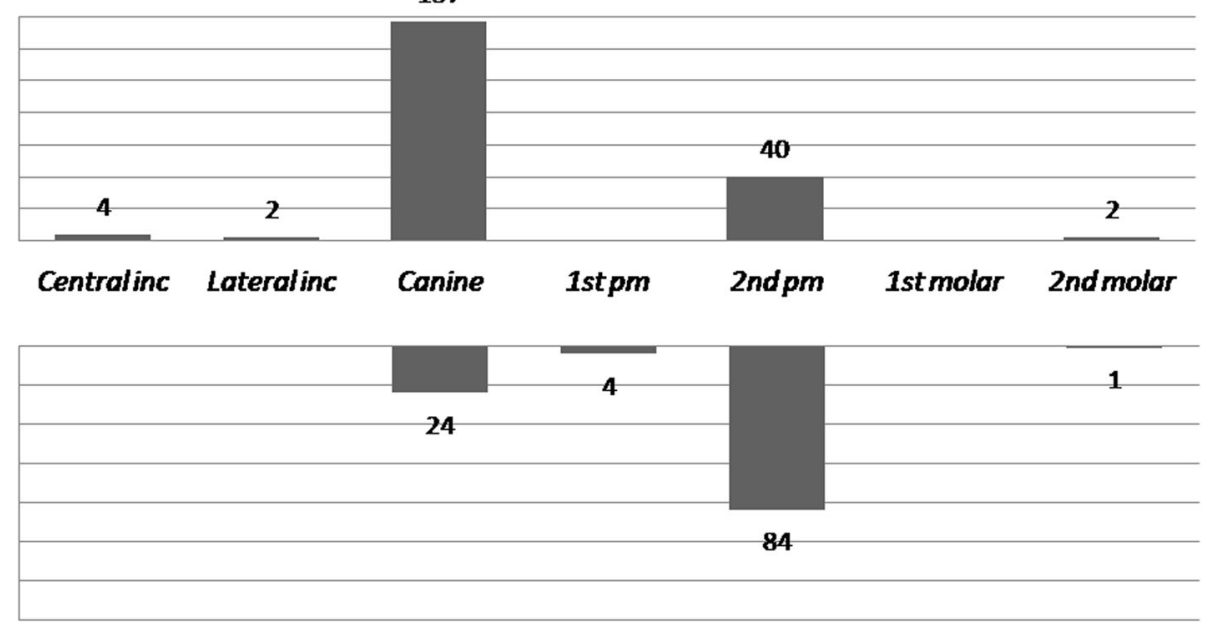

Mandibular teeth

Fig. 1 Distribution of the 297 impacted teeth between the maxilla and the mandible. Inc.: incisor, 1st pm: first premolar, 2nd pm: second premolar 
Table 1 Severity of permanent tooth impaction in the vertical, horizontal, and angular positions in relation to different grouping factors. (younger age group $=15-25 \mathrm{yr}$., older age group $=25.1-40 \mathrm{yr} ., \mathrm{M} \times 2=$ maxillary lateral incisor)

\begin{tabular}{|c|c|c|c|c|c|c|c|c|c|c|c|c|c|c|c|}
\hline \multirow{3}{*}{$\begin{array}{l}\text { Position of } \\
\text { the impacted } \\
\text { tooth }(n=297)\end{array}$} & \multicolumn{15}{|c|}{ Factors assessed in relation to the severity of impaction using Wilcoxon-Mann-Whitney test ( $P$-value) } \\
\hline & \multicolumn{3}{|l|}{ Age } & \multicolumn{3}{|c|}{ Gender } & \multicolumn{3}{|c|}{ Tooth agenesis } & \multicolumn{3}{|c|}{ Microdontia of Mx2 } & \multicolumn{3}{|c|}{ Retained deciduous } \\
\hline & $\begin{array}{l}\text { Younger } \\
\text { Mean } \\
\text { rank }\end{array}$ & $\begin{array}{l}\text { Older } \\
\text { Mean } \\
\text { rank }\end{array}$ & P & $\begin{array}{l}\text { Male } \\
\text { Mean } \\
\text { rank }\end{array}$ & $\begin{array}{l}\text { Female } \\
\text { Mean } \\
\text { rank }\end{array}$ & ie & $\begin{array}{l}\text { Yes } \\
\text { Mean } \\
\text { rank }\end{array}$ & $\begin{array}{l}\text { No } \\
\text { Mean } \\
\text { rank }\end{array}$ & $\bar{u}$ & $\begin{array}{l}\text { Yes } \\
\text { Mean } \\
\text { rank }\end{array}$ & $\begin{array}{l}\text { No } \\
\text { Mean } \\
\text { rank }\end{array}$ & $\overline{\mathrm{ue}}$ & $\begin{array}{l}\text { Yes } \\
\text { Mean } \\
\text { rank }\end{array}$ & $\begin{array}{l}\text { No } \\
\text { Mean } \\
\text { rank }\end{array}$ & P-valu \\
\hline Vertical & 129.2 & 132.6 & 0.675 & 130.8 & 130.3 & 0. & 1 & 131.2 & 0. & 141.0 & 128.8 & 0. & 130.3 & 130.7 & 0.901 \\
\hline ri- & 47.0 & 152.5 & 0.573 & 140.5 & 156.8 & 0.087 & 138.7 & 150.6 & 0.398 & 175.4 & 145.0 & $0.030^{*}$ & 156.8 & 143.1 & 0.150 \\
\hline ngle of impaction & 140.5 & 163.9 & $0.012^{*}$ & 137.9 & 159.1 & $0.018^{*}$ & 139.9 & 150.4 & 0.430 & 168.6 & 146.0 & 0.088 & 154.7 & 144.7 & 0.267 \\
\hline
\end{tabular}

${ }^{*}: P<0.05$ (statistically significant difference)

horizontal impaction position was less severe $(P=0.041)$. Similarly, the microdontia of the maxillary lateral incisor only significantly affected the horizontal $(P=0.024)$ and angular $(P=0.010)$ positions of the impacted mandibular second premolar, but it was more severe. A retained deciduous predecessor was linked to a reduced severity of the vertical impaction of the mandibular second premolar $(P=0.030)$, a reduced severity of the horizontal impaction of the maxillary second premolar $(P=0.037)$, and an increased severity of the angular impaction of the mandibular canine $(P=0.041)$. Nevertheless, a retained deciduous predecessor had no effect on the severity of the impaction of the maxillary canine.

\section{Discussion}

An unerupted tooth is considered a clinical challenge for the orthodontist in terms of diagnosis, anchorage management and treatment duration. A treatment difficulty index published by Pitt et al. in 2006 has been used to predict and evaluate such a challenge [14]. Part of the difficulty score used in this index is based on ranking the position of the impacted teeth. The higher the rank of the position of the impacted tooth, the more difficult it is to align [15, 20, 24]. In our study, we investigated the effects of a number of factors on the severity of impaction. The results showed that different tooth types vary significantly in the severity of impaction and, consequently, in the difficulty of treatment. Among the four most frequently impacted teeth found in our study, the maxillary canine was the most severely impacted $(P<0.001)$, whereas the mandibular second premolar was the least severely impacted $(P<0.001)$. Therefore, tooth type could be another factor that must be considered to predict treatment difficulty of impacted teeth.

The second factor affecting the severity of tooth impaction that was investigated in our study was age. The results suggested that, as time passed, there might be a risk of the position of the impacted tooth worsening, especially increasing the angle of its long axis towards the midline $(P=0.012)$. Therefore, the earlier the diagnosis and treatment of the impacted tooth, the less complicated and shorter the treatment duration will be, as suggested by the treatment difficulty index [14]. The angular impaction of the maxillary canine was significantly worse in the older age group $(P=0.012)$. This finding might suggest that a severely impacted tooth can migrate and cross the midline with time, which stresses the importance of an early diagnosis and treatment planning.

There might have been differences between genders when the prevalence of dental impaction was investigated [11, 13]. Nevertheless, none of the previous studies reported the effect of gender on the severity of impaction of permanent teeth. In the current study, the Wilcoxon-Mann-Whitney test showed a significantly more severe angular tooth impaction in females compared to males $(P=0.018)$. When tooth type was taken into consideration, the maxillary canine had worse horizontal $(P=0.001)$ and angular $(P=0.003)$ impactions in females. This finding might indicate $\mathrm{x}$-linked genetic factors contribute to the aetiology and prognosis of maxillary canine impactions. It also suggests that when maxillary canine impaction is diagnosed in females, it is predicted to be more severe, and therefore, a more difficult and lengthy treatment is to be expected. Furthermore, permanent teeth erupt earlier in females; therefore, early inspection and palpation of maxillary canines and early interceptive procedures [16] should be considered crucial clinical routines in female patients.

Tooth agenesis was the next factor investigated for its effect on the severity of tooth impaction in the present study. Tooth agenesis was proven to be significantly associated with a higher incidence of impaction of permanent teeth $[25,27-29]$; however, only a few studies have investigated the effects of this factor on the severity of impaction [23, 30,31]. Our results showed that tooth agenesis was associated with a reduced severity of impaction of all teeth in general, but not on a significant level. Only the mandibular second premolar had a significant reduction in the severity of the horizontal impaction $(P=0.041)$ when tooth agenesis was present.

Unlike tooth agenesis, microdontia of the maxillary lateral incisor was associated with more severe impaction, especially in the horizontal position $(P=0.030)$. Surprisingly, the most severely affected tooth was not 


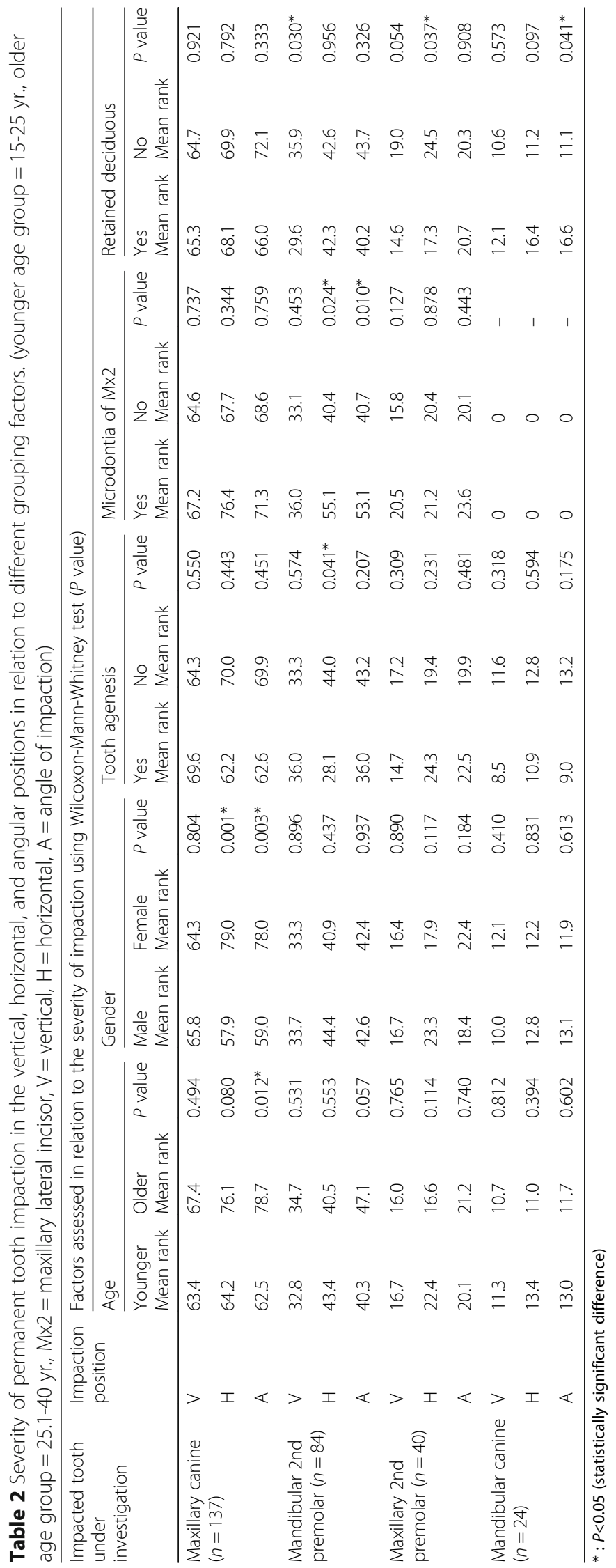


the maxillary canine, as expected [32, 33]; it was the mandibular second premolar, especially in the horizontal $(P=0.024)$ and angular $(P=0.010)$ positions. A genetic link between dental anomalies affecting the maxillary lateral incisor and the mandibular second premolar was suggested by previous studies [27, 29, 34]; however, none of those studies looked specifically on the severity of impaction. Similarly, retained deciduous teeth were not researched previously for their effects on the severity of the impaction of permanent teeth. The findings of the present study suggest that maintaining the deciduous second molar might be recommended, as its presence was linked to a reduced severity of the vertical impaction of the mandibular second premolar $(P=0.030)$ and the horizontal impaction of the maxillary second premolar $(P=0.037)$. On the other hand, our results emphasize the importance of timely extraction of the mandibular deciduous canine if the permanent successor shows risk of impaction, because a retained deciduous tooth was significantly associated with an increased severity of the angular impaction $(P=0.041)$ of the mandibular canine.

\section{Conclusions}

1) With age, the angle of an impacted tooth might increase in severity; therefore, early diagnosis and treatment is mandatory, especially for the maxillary canines.

2) Females suffer from more severe impaction of teeth in general, and of the maxillary canine in particular. Consequently, and because teeth erupt earlier in females, it is crucial to diagnose impaction earlier in females and carryout any necessary preventive or interceptive orthodontic procedures.

3) The presence of microdontia of the maxillary lateral incisor is significantly associated with more severe impaction, which emphasizes the importance of tooth size investigations in young patients and carrying out further analysis for those with small laterals.

4) Finally, the results of the current study revealed a significant association between retained deciduous predecessors and the severity of impaction of their successors. Nevertheless, an observational longitudinal study is required to produce solid clinical recommendations.

\section{Abbreviations}

A: Angle of impaction; H: Horizontal; Mx2: Maxillary lateral incisor; n: number; SD: Standard deviation; V: Vertical; $X^{2}$ : Chi-squared test; yr: years

\section{Funding}

This study was funded by the Deanship of Academic Research, The University of Jordan. The funding body played no role in the design of the study, collection, analysis, or interpretation of data or in writing the manuscript.

\section{Availability of data and materials}

The datasets used and/or analysed during the current study are available from the corresponding author upon reasonable request.

\section{Disclaimers}

The views expressed in the submitted article are the authors' own and not an official position of the institution or funder.

\section{Authors' contributions}

$\mathrm{MA}, \mathrm{MH}$, and NDO made substantial contributions to the conception and design of the study. MA and AA contributed to the acquisition, analysis, and interpretation of data. All authors were involved in drafting the manuscript or revising it critically for important intellectual content. All authors read and approved the final manuscript. All authors agreed to be accountable for all aspects of the work in ensuring that questions related to the accuracy or integrity of any part of the work are appropriately investigated and resolved.

\author{
Authors' information \\ MA \\ Associate Professor in Orthodontics/ The University of Jordan. \\ Assistant Dean of Accreditation and Development/ The University of Jordan. \\ Senior Orthodontic consultant/ Jordan University Hospital. \\ BDS, MSc (England), M-Orth (Edin), PhD (England).
}

\section{Ethics approval and consent to participate}

No ethical approval or consent was necessary to handle the data used in our study according to the National Research Ethics Service/UK, which states, "Research limited to secondary use of information previously collected in the course of normal care (without an intention to use it for research at the time of collection) is generally excluded from research ethic committee review, provided that the patients or service users are not identifiable to the research team in carrying out the research". The same concept was included in the textbook, "Introduction to Research Methodology for Specialists and Trainees," edited by P. M. Shaughn O'Brien and Fiona Broughton Pipkin (third edition, 2017, Cambridge University Press), chapter 24 page 191

Consent for publication

Not applicable.

\section{Competing interests}

The authors declare that they have no competing interests.

\section{Publisher's Note}

Springer Nature remains neutral with regard to jurisdictional claims in published maps and institutional affiliations.

\section{Author details}

${ }^{1}$ Department of Orthodontics, Faculty of Dentistry, The University of Jordan, Amman 11942, Jordan. ${ }^{2}$ Department of Oral and Maxillofacial Surgery, School of Dentistry, The University of Jordan, Amman, Jordan. ${ }^{3}$ Department of Conservative Dentistry, Faculty of Dentistry, The University of Jordan, Amman, Jordan. ${ }^{4}$ Department of Oral Medicine, Faculty of Dentistry, The University of Jordan, Amman, Jordan.

Received: 7 November 2017 Accepted: 22 October 2018

Published online: 01 November 2018

References

1. Bjork A, Skieller V. Facial development and tooth eruption. An implant study at the age of puberty. Am J Orthod. 1972;62:339-83.

2. Suri L, Gagari E, Vastardis H. Delayed tooth eruption: pathogenesis, diagnosis, and treatment. A literature review. Am J Orthod Dentofac Orthop. 2004;126:432-45.

3. Ten Cate AR. Oral histology : development, structure, and function. St. Louis; London: Mosby; 1998. 
4. Lagana G, Venza N, Borzabadi-Farahani A, Fabi F, Danesi C, Cozza P. Dental anomalies: prevalence and associations between them in a large sample of non-orthodontic subjects, a cross-sectional study. BMC Oral Health. 2017:17:62.

5. Uslu O, Akcam MO, Evirgen S, Cebeci I. Prevalence of dental anomalies in various malocclusions. Am J Orthod Dentofac Orthop. 2009;135:328-35.

6. Fardi A, Kondylidou-Sidira A, Bachour Z, Parisis N, Tsirlis A. Incidence of impacted and supernumerary teeth-a radiographic study in a north Greek population. Med Oral Patol Oral Cir Bucal. 2011;16:e56-61.

7. Grover PS, Lorton L. The incidence of unerupted permanent teeth and related clinical cases. Oral Surg Oral Med Oral Pathol. 1985;59:420-5.

8. Dachi SF, Howell FV. A survey of 3,874 routine full-month radiographs. II A study of impacted teeth. Oral Surg Oral Med Oral Pathol. 1961;14:1165-9.

9. al-Emran S, Wisth PJ, Boe OE. Prevalence of malocclusion and need for orthodontic treatment in Saudi Arabia. Community Dent Oral Epidemiol. 1990;18:253-5.

10. Thilander B, Pena L, Infante C, Parada SS, de Mayorga C. Prevalence of malocclusion and orthodontic treatment need in children and adolescents in Bogota, Colombia. An epidemiological study related to different stages of dental development. Eur J Orthod. 2001;23:153-67.

11. Aitasalo K, Lehtinen R, Oksala E. An orthopantomographic study of prevalence of impacted teeth. Int J Oral Surg. 1972;1:117-20.

12. Kazanci F, Celikoglu M, Miloglu O, Yildirim H, Ceylan I. The frequency and characteristics of mesiodens in a Turkish patient population. Eur J Dent. 2011;5:361-5.

13. Hou R, Kong L, Ao J, Liu G, Zhou H, Qin R, et al. Investigation of impacted permanent teeth except the third molar in Chinese patients through an $\mathrm{X}$ ray study. J Oral Maxillofac Surg. 2010;68:762-7.

14. Pitt $S$, Hamdan A, Rock P. A treatment difficulty index for unerupted maxillary canines. Eur J Orthod. 2006;28:141-4

15. Crescini A, Nieri M, Buti J, Baccetti T, Pini Prato GP. Orthodontic and periodontal outcomes of treated impacted maxillary canines. Angle Orthod. 2007;77:571-7.

16. Ericson S, Kurol J. Early treatment of palatally erupting maxillary canines by extraction of the primary canines. Eur J Orthod. 1988;10:283-95.

17. Stewart JA, Heo G, Glover KE, Williamson PC, Lam EW, Major PW. Factors that relate to treatment duration for patients with palatally impacted maxillary canines. Am J Orthod Dentofac Orthop. 2001;119:216-25.

18. Power SM, Short MB. An investigation into the response of palatally displaced canines to the removal of deciduous canines and an assessment of factors contributing to favourable eruption. Br J Orthod. 1993;20:215-23.

19. Burch J, Ngan P, Hackman A. Diagnosis and treatment planning for unerupted premolars. Pediatr Dent. 1994;16:89-95.

20. Bazargani F, Magnuson A, Dolati A, Lennartsson B. Palatally displaced maxillary canines: factors influencing duration and cost of treatment. Eur J Orthod. 2013;35:310-6.

21. Langlais RP, Langland OE, Nortje CJ. Diagnostic imaging of the jaws. Baltimore; London: Williams \& Wilkins; 1995.

22. Andreasen JO, Petersen JK, Laskin DM. Textbook and color atlas of tooth impactions : diagnosis, treatment, prevention. Copenghagen: Munksgaard; 1997.

23. Navarro J, Cavaller M, Luque E, Tobella ML, Rivera A. Dental anomaly pattern (DAP): agenesis of mandibular second premolar, distal angulation of its antimere and delayed tooth formation. Angle Orthod. 2014;84:24-9.

24. Stivaros N, Mandall NA. Radiographic factors affecting the management of impacted upper permanent canines. J Orthod. 2000;27:169-73.

25. Al-Abdallah M, AlHadidi A, Hammad M, Al-Ahmad H, Saleh R. Prevalence and distribution of dental anomalies: a comparison between maxillary and mandibular tooth agenesis. Am J Orthod Dentofac Orthop. 2015;148:793-8.

26. Lagana G, Lombardi CC, Franchi L, Cozza P. Tooth agenesis: dento-skeletal characteristics in subjects with orthodontic treatment need. Eur J Paediatr Dent. 2011;12:17-20.

27. Garib DG, Peck S, Gomes SC. Increased occurrence of dental anomalies associated with second-premolar agenesis. Angle Orthod. 2009;79:436-41.

28. Peck S, Peck L, Kataja M. Concomitant occurrence of canine malposition and tooth agenesis: evidence of orofacial genetic fields. Am J Orthod Dentofac Orthop. 2002;122:657-60.

29. Garib DG, Alencar BM, Lauris JR, Baccetti T. Agenesis of maxillary lateral incisors and associated dental anomalies. Am J Orthod Dentofac Orthop. 2010;137:732 e731-736; discussion 732-733.
30. Kure K, Arai K. Mesiodistal inclination of the unerupted second premolar in the mandible of Japanese orthodontic patients with incisor agenesis. Angle Orthod. 2015;85:949-54.

31. Shalish M, Peck S, Wasserstein A, Peck L. Malposition of unerupted mandibular second premolar associated with agenesis of its antimere. Am J Orthod Dentofac Orthop. 2002;121:53-6.

32. Peck $S$, Peck $L$, Kataja M. Prevalence of tooth agenesis and peg-shaped maxillary lateral incisor associated with palatally displaced canine (PDC) anomaly. Am J Orthod Dentofac Orthop. 1996;110:441-3.

33. Oliver RG, Mannion JE, Robinson JM. Morphology of the maxillary lateral incisor in cases of unilateral impaction of the maxillary canine. Br J Orthod. 1989;16:9-16.

34. Baccetti T. A controlled study of associated dental anomalies. Angle Orthod. 1998;68:267-74

\section{Ready to submit your research? Choose BMC and benefit from:}

- fast, convenient online submission

- thorough peer review by experienced researchers in your field

- rapid publication on acceptance

- support for research data, including large and complex data types

- gold Open Access which fosters wider collaboration and increased citations

- maximum visibility for your research: over $100 \mathrm{M}$ website views per year

At BMC, research is always in progress.

Learn more biomedcentral.com/submissions 